\title{
An Adult-Like Pattern of Ocular Dominance Columns in Striate Cortex of Newborn Monkeys prior to Visual Experience
}

\author{
Jonathan C. Horton and Davina R. Hocking \\ Beckman Vision Center, University of California, San Francisco, California 94143-0730
}

In macaque monkeys, the geniculocortical afferents serving each eye segregate in layer IVc of striate cortex during early life into a pattern of alternating inputs called ocular dominance columns. It has been disputed whether visual experience is necessary for the formation of ocular dominance columns. To settle this issue, fetal monkeys were delivered prematurely by Caesarean section at embryonic day 157 (E157), $8 \mathrm{~d}$ before the end of normal gestation. To avoid light exposure, the Caesarean section and all subsequent feedings and procedures were done in absolute darkness, using infrared night-vision goggles. Tritiated proline was injected into the right eye $1 \mathrm{~d}$ after delivery (E158). One week later at postnatal age 0 (P0), the equivalent of a full-term pregnancy (E165/P0), alternate sections of unfolded and flattened visual cortex were prepared for autoradiography or cytochrome oxidase (CO). All three newborns studied at E165/P0 had well segregated ocular dominance columns orga- nized into the characteristic mosaic present in adults. In the upper layers, a mature pattern of CO patches (also known as blobs or puffs) was visible, aligned with the ocular dominance columns in layer IVc. Every other row of patches in layers II,III was labeled by $\left.{ }^{3} \mathrm{H}\right]$ proline. In $\mathrm{V} 2$, a distinct system of alternating thick-pale-thin-pale CO stripes was present. These findings indicate that stimulation of the retina by light is not necessary for the development of columnar systems in the visual cortex. Ocular dominance columns, patches, and V2 stripes all are well formed before visual experience. Even the thalamic input to the patches in the upper layers of striate cortex is segregated by eye in newborns.

Key words: ocular dominance columns; macaque striate cortex; cytochrome oxidase patches; visual experience; cortical development; cytochrome oxidase stripes
In striate cortex of the fetal monkey, inputs serving each eye are intermingled completely in layer IVc at embryonic day 124 (E124), 6 weeks before birth (Rakic, 1976, 1977). By 6 weeks after birth, these inputs have assembled into an adult-like pattern of alternating stripes called ocular dominance columns (LeVay et al., 1980). Determining how geniculocortical afferents become organized into ocular dominance columns is important for understanding the development of the cerebral cortex and for learning how this process might be affected by diseases like amblyopia and strabismus.

There is controversy regarding whether visual experience is rcquircd for ocular dominance columns to form. Rakic (1977) found continuous label in layer IVc after $\left[{ }^{3} \mathrm{H}\right]$ proline eye injection in monkeys at E144, 3 weeks before birth, although grain counts in a few areas showed slight fluctuations in density, which hinted at nascent columns. Similar findings were reported by Hubel et al. (1977) in a single monkey studied $6 \mathrm{~d}$ after birth. In this animal, no columns were detected in the cortex contralateral to the $\left[{ }^{3} \mathrm{H}\right]$ proline-injected eye. In the ipsilateral cortex, a few faint bands that were thought to represent precursors of the ocular dominance columns were visible. By 3 weeks after birth, the

\footnotetext{
Received Sept. 14, 1995; revised Oct. 18, 1995; accepted Oct. 27, 1995.

This work was supported by National Institutes of Health Grant R01-EY10217 and by That Man May See, Inc. The Primate Center is supported by National Institutes of Health Base Grant RR00169. We thank the staff of the California Regional Primate Research Center (Davis, CA) for their help, especially John Anderson, David Robb, and Jenny Short. We also thank Robin Troyer for help with these experiments. Julie Schnapf, Ken Miller, and David Sretavan provided useful comments on this manuscript.

Correspondence should be addressed to Dr. Jonathan C. Horton, Beckman Vision Center, 10 Kirkham Street, University of California, San Francisco, CA 94143-0730. Copyright (C) 1996 Society for Neuroscience $0270-6474 / 96 / 161791-17 \$ 05.00 / 0$
}

ocular dominance columns appeared nearly as well formed as in the adult (LeVay et al., 1980).

These experiments suggest that geniculocortical afferents serving each eye essentially are intermixed during fetal life and then begin to segregate after birth. Visual experience is thought perhaps to catalyze this rapid postnatal development. Evidence favoring this view has come from studies in kittens, which have shown that segregation of geniculocortical afferents begins only after eye opening at age 10-14 d (LeVay et al., 1978; LeVay and Stryker, 1979). Swindale (1981) has reported that ocular dominance columns are absent in dark-reared cats, a finding that implies an essential role for visual experience in the development of ocular dominance columns. However, other investigators have reported that ocular dominance columns actually do form in dark-reared cats (Mower et al., 1985; Stryker and Harris, 1986).

To resolve the question of whether visual experience or light exposure is required for the segregation of geniculocortical afferents, we studied the development of ocular dominance columns in late fetal monkeys. All previous studies addressing this issue have allowed some light or visual exposure to occur, either between the time of birth and the initiation of dark-rearing, or when eye injection is made with proline. The duration of this visual experience usually is unclear although, presumably, it was kept as short as possible. It is conceivable that any light exposure, however brief, could be sufficient to trigger the process of column segregation, which then could run to completion without additional retinal stimulation. Experiments in dark-reared cats have shown that exposure to light for only $1 \mathrm{hr}$ is enough to alter cortical plasticity (Mower et al., 1983) and to induce immediate early gene expression (Rosen et al., 1992). To eliminate visual experience totally, we took elaborate measures to maintain our animals in 

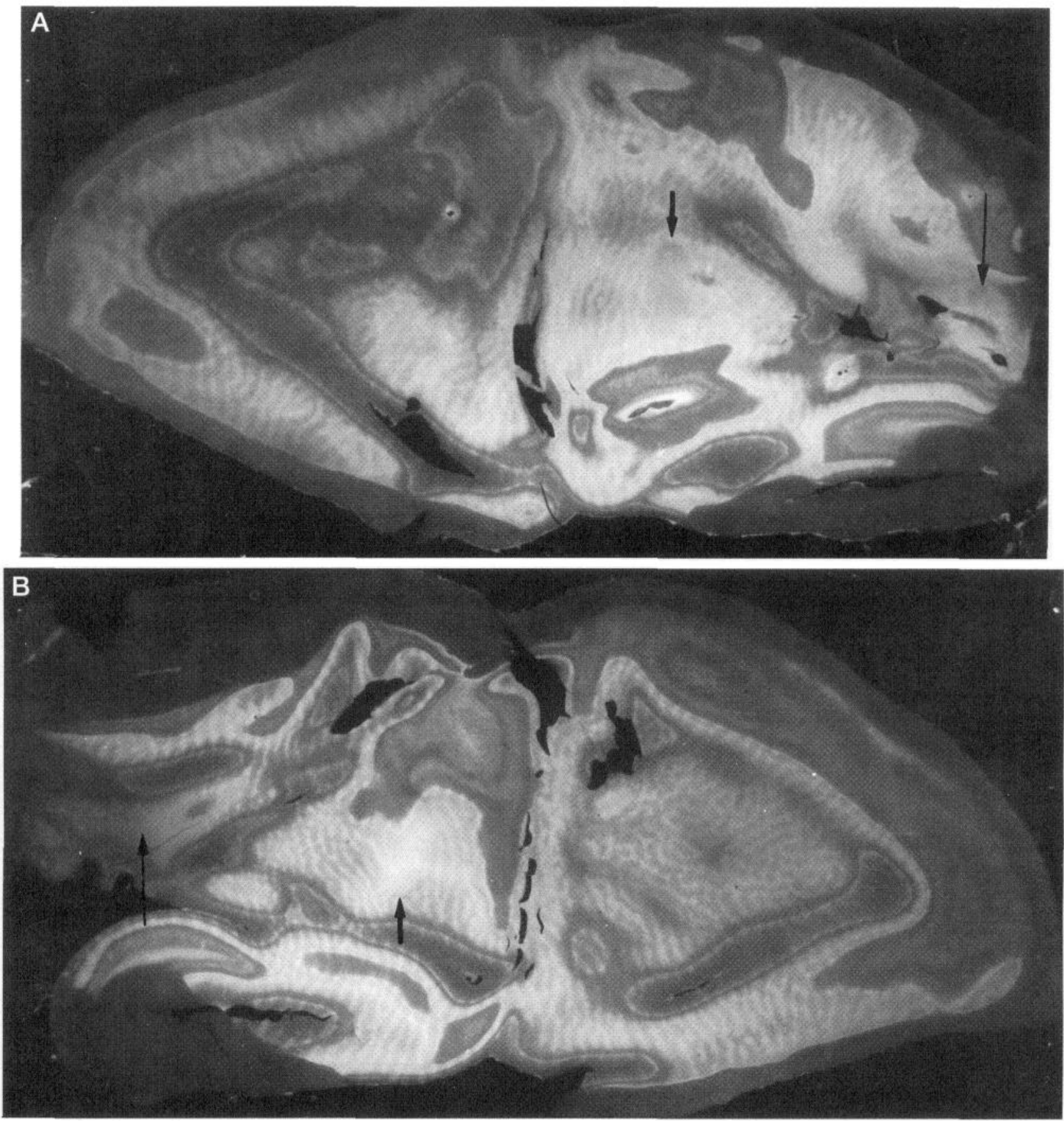

Figure 1. Autoradiograph of a single flattened section from dark-reared newborn monkey $1(\mathrm{E} 165 / \mathrm{P} 0)$ through the entire left $(A)$ and right $(B)$ striate cortex. In all figures, cortical autoradiographs are shown in dark-field and the bright label represents transneuronal input from the injected right eye. Note that ocular dominance columns are clearly visible throughout layer IVc on both sides, except in the monocular crescent (long arrows) and blind-spot representations (short arrows). For scale, see Figure 2.

absolute darkness, delivering them by Caesarean section and performing all procedures using infrared night-vision goggles to prevent light exposure.

\section{MATERIALS AND METHODS}

Animals and surgical procedures. Four rhesus monkeys (Macaca mulatta) were used for these experiments. They were bred from timed matings of four different sets of unrelated parents at the California Regional Primate Research Center (Davis, CA). After the second month of pregnancy, the mothers were housed indoors in a dimly illuminated room (average luminance, $0.86 \mathrm{~cd} / \mathrm{m}^{2}$ ) to prevent transabdominal and transuterine light exposure of the fetus.

At E157, three fetuses were delivered $8 \mathrm{~d}$ prematurely by Caesarean section. The pregnant mothers were sedated with ketamine $\mathrm{HCl}(10$ $\mathrm{mg} / \mathrm{kg}$ ), intubated, and placed under general anesthesia with $\mathrm{N}_{2} \mathrm{O} / \mathrm{O}_{2}$ (2:1) and $2 \%$ isoflurane. After shaving the abdomen and draping the surgical site, we extinguished all lights and donned infrared night-vision goggles (Intevac model AN/PVS7B). We waited $40 \mathrm{~min}$ to achieve full dark adaptation and then searched with the night-vision goggles to locate all light leaks in the operating room. The light leaks were covered with thick black tape until we had achieved absolute darkness. At this point, 
Table 1. Measurements of ocular dominance column mosaics

\begin{tabular}{|c|c|c|c|c|c|c|}
\hline & & y 1 & & y 2 & Mo & 4 \\
\hline Age & Newborn (E1 & & Newborn (E1 & & 2 weeks (P16) & \\
\hline Sex & Male & & Female & & Female & \\
\hline Hemisphere & left & right & left & right & left & right \\
\hline Area V1 $\left(\mathrm{mm}^{2}\right)$ & 993 & 928 & 1017 & 1007 & 1259 & 1243 \\
\hline & 1020 & 957 & 1045 & 1027 & 1289 & 1248 \\
\hline Operculum & & & & & & \\
\hline Left eye columns $\left(\mathrm{mm}^{2}\right)$ & $185(45.9 \%)$ & $223(48.9 \%)$ & $223(47.8 \%)$ & $238(51.5 \%)$ & $253(47.7 \%)$ & $284(51.5 \%)$ \\
\hline & $205(49.4 \%)$ & $236(50.2 \%)$ & $254(52.7 \%)$ & $247(51.7 \%)$ & $271(50.6 \%)$ & $298(53.6 \%)$ \\
\hline Right eye columns (mml $\left.{ }^{2}\right)$ & $218(54.1 \%)$ & $233(51.1 \%)$ & $244(52.2 \%)$ & $224(48.5 \%)$ & $277(52.3 \%)$ & $267(48.5 \%)$ \\
\hline & $210(50.6 \%)$ & $234(49.8 \%)$ & $228(47.3 \%)$ & $231(48.3 \%)$ & $265(49.4 \%)$ & $258(46.4 \%)$ \\
\hline Periphery & & & & & & \\
\hline Left eye columns $\left(\mathrm{mm}^{2}\right)$ & $167(38.5 \%)$ & $158(53.4 \%)$ & $148(44.3 \%)$ & $201(53.9 \%)$ & $165(37.9 \%)$ & $211(52.8 \%)$ \\
\hline & $178(40.4 \%)$ & $177(56.9 \%)$ & $170(47.4 \%)$ & $220(57.7 \%)$ & $183(40.9 \%)$ & $235(57.2 \%)$ \\
\hline Right eye columns $\left(\mathrm{mm}^{2}\right)$ & $267(61.5 \%)$ & $138(46.6 \%)$ & $186(55.7 \%)$ & $172(46.1 \%)$ & $270(62.1 \%)$ & $189(47.2 \%)$ \\
\hline & $263(59.6 \%)$ & $134(43.1 \%)$ & $189(52.6 \%)$ & $161(42.3 \%)$ & $264(59.1 \%)$ & $176(42.8 \%)$ \\
\hline Unreconstructable area $\left(\mathrm{mm}^{2}\right)$ & 76 & 108 & 122 & 105 & 212 & 227 \\
\hline & 78 & 110 & 115 & 104 & 221 & 219 \\
\hline Column pairs along $\mathrm{V} 1-\mathrm{V} 2$ & & & & & & \\
\hline border & 116 & 115 & 122 & 125 & 118 & 122 \\
\hline Average column width along & & & & & & \\
\hline $\mathrm{V} 1-\mathrm{V} 2$ border $(\mu \mathrm{m})$ & 501 & 520 & 480 & 485 & 572 & 549 \\
\hline Optic disc area $\left(\mathrm{mm}^{2}\right)$ & 8 & 10 & 11 & 9 & 16 & 15 \\
\hline & 8 & 10 & 10 & 9 & 16 & 17 \\
\hline Monocular crescent area $\left(\mathrm{mm}^{2}\right)$ & 72 & 58 & 83 & 58 & 66 & 50 \\
\hline & 78 & 56 & 80 & 55 & 69 & 47 \\
\hline
\end{tabular}

Data in italics were obtained manually by cutting and weighing the drawings. No quantitative measurements were made of monkey 3 .

operating with the aid of the night-vision goggles, we performed a hysterotomy through a standard midline incision and delivered the fetus. After we had ascertained that the fetus was stable and healthy, we placed it into a specially constructed, light-tight, ventilated incubator maintained at $32^{\circ} \mathrm{C}$ and immediately transported it to the University of California, San Francisco.

The baby monkeys were housed in the light-tight incubator at $32^{\circ} \mathrm{C}$ for the next $8 \mathrm{~d}$. The incubator was kept in a special darkroom within our animal care facility that was equipped with a double light-lock entrance that allowed one to enter without exposing the inner room to light. The monkeys were fed $5 \%$ dextrose every $2 \mathrm{hr}$ for the first $24 \mathrm{hr}$. Thereafter, they received Enfamil every $2 \mathrm{hr}$, except from midnight to 6:00 A.M. Between feedings the babies slept most of the time.

At E158, the day after Caesarean delivery, an injection of $2 \mathrm{mCi}$ of $\mathrm{L}-\left[2,3,4,5-{ }^{3} \mathrm{H}\right]$ proline, specific activity $102-106 \mathrm{Ci} / \mathrm{mmol}$ (Amersham, Arlington Hcights, IL), was made into the right cye to label the retinogeniculocortical pathway by transneuronal autoradiography. The label was dried under $\mathrm{N}_{2}$ gas and reconstituted in $20 \mu \mathrm{l}$ of balanced salt solution. After fasting for $2 \mathrm{hr}$, the baby monkeys were anesthetized with ketamine $\mathrm{HCl}(5 \mathrm{mg}$, i.m.) and 1 drop of topical $4 \%$ tetracaine $\mathrm{HCl}$. Using night-vision goggles, an injection was made through the sclera 3.5 $\mathrm{mm}$ from the superotemporal limbus with a 29-gauge needle. It was inserted $8 \mathrm{~mm}$ into the eye to place the tracer into the mid-vitreous.

The three baby monkeys delivered by Caesarean section were kept in complete darkness at all times to avoid any visual experience or light exposure. We checked the darkroom nursery for light leaks with nightvision goggles every $2 \mathrm{hr}$ at the time of feedings; none were found. Additionally, sheets of photographic paper were placed in the darkroom at the beginning of the experiment. These were developed at the end of the experiment to verify by the lack of fogging that no inadvertent light exposure had occurred.

For comparison with the three dark-reared newborn monkeys, a fourth monkey was raised under completely different conditions. This animal was born naturally at E165 and raised under normal lighting conditions in the nursery. An injection of $\left[{ }^{3} \mathrm{H}\right]$ proline was made into the right eye at postnatal day $9(\mathrm{P} 9)$.

Histological procedures. At E165, the three dark-reared monkeys were given a lethal injection of $150 \mathrm{mg}$ of pentobarbital sodium into the peritoneal cavity. This allowed 1 week for transport of $\left[{ }^{3} \mathrm{H}\right]$ proline to the visual cortex after tracer injection into the eye at E158. E165 is the average duration of normal pregnancy in rhesus monkeys. Therefore, we arranged the dates of Cacsarean section, eye injection, and perfusion so that the monkeys were equivalent to full-term neonates (E165/P0) at the time of death. They were perfused through the left ventricle with 1 liter of normal saline followed by 1 liter of $2 \%$ paraformaldehyde. The lateral geniculate bodies and occipital lobes were removed and placed into $0.1 \mathrm{M}$ PBS. Striate cortex was removed from the white matter of each occipital lobe, unfolded, cryoprotected overnight with $30 \%$ sucrose, and frozen flat by placing the pial surface down on a slide coated with Saran Wrap while pressing gently on the white matter surface with a plastic bag of powdered dry ice (Horton, 1984). Sections were cut at $30 \mu \mathrm{m}$ on a freezing microtome and processed alternately for autoradiography or cytochrome oxidase (CO) activity (Wong-Riley, 1979). For the cortical autoradiographs, the Kodak NTB2 emulsion was exposed for 10 weeks. The lateral geniculate bodies were cut at $25 \mu \mathrm{m}$ and exposed for 2 weeks.

The single light-reared monkey, born at E165 and injected with $\left[{ }^{3} \mathrm{H}\right]$ proline at $\mathrm{P} 9$, was perfused on $\mathrm{P} 16$.

Image analysis. The autoradiographs were photographed using Technical Pan film (Eastman Kodak, Rochester, NY), processed with Technidol (Eastman Kodak) developer, and printed on grade 4 Rapitone (Agfa) paper. Photomontages were prepared of the ocular dominance columns in layer IVc $\beta$. The pattern of ocular dominance columns in the photomontages then was traced by pen and ink onto acetate sheets. These pen-and-ink figures were scanned as continuous-tone images and analyzed using Mocha software (Jandel Scientific, San Rafael, CA). To measure column areas, pixels were grouped according to 256 levels of gray, yielding a $\mathbf{U}$-shaped histogram. The exact gray level for defining black versus white (left eye column vs right eye column) was determined 

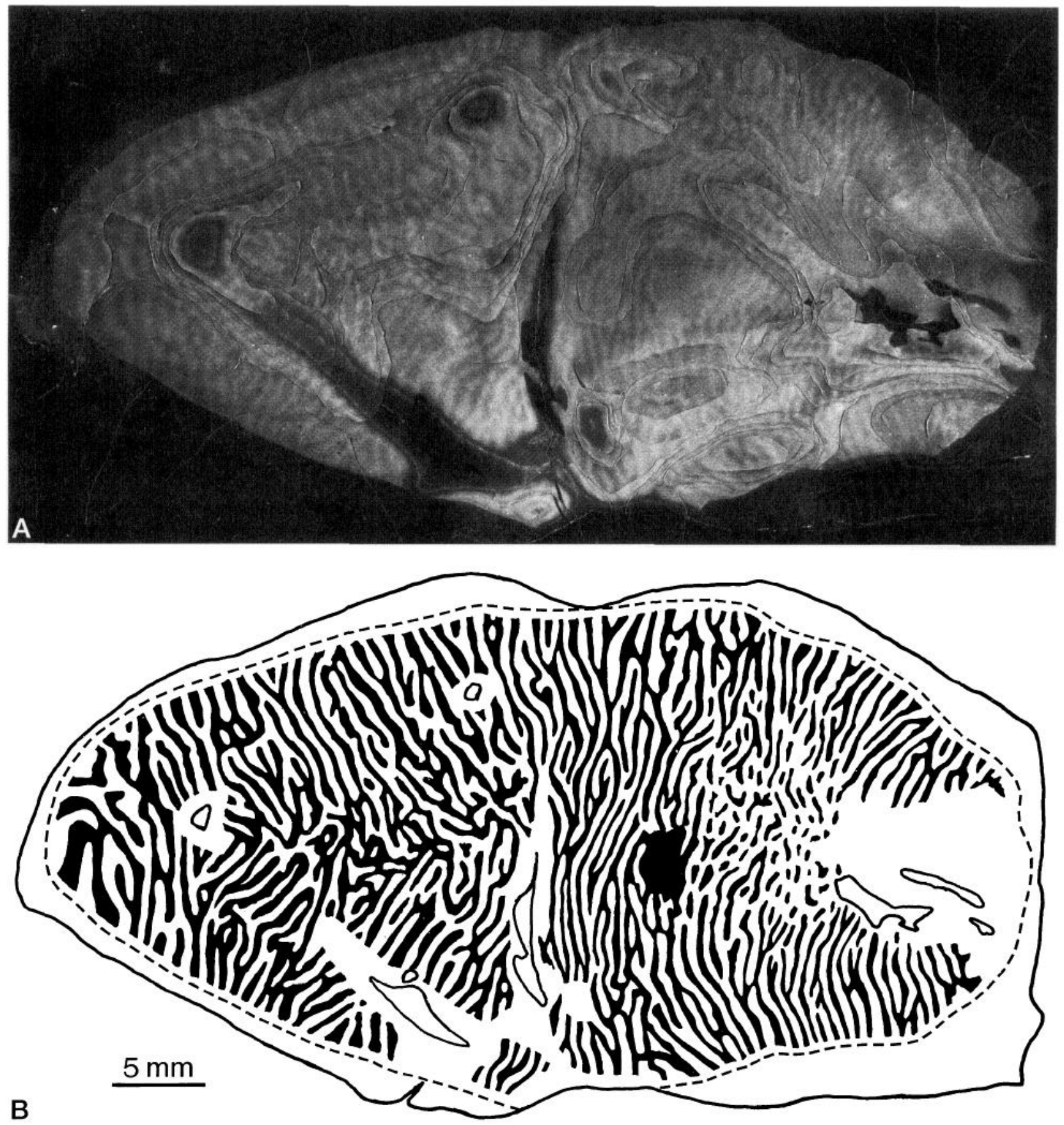

Figure 2. Photomontage and drawing of the ocular dominance columns in layer IVc $\beta$ from the left $(A, B)$ and right $(C, D)$ striate cortex of monkey 1 , prepared from a series of autoradiographs like the example shown in Figure 1. The ocular dominance columns are well segregated and organized into an adult-like pattern at E165/P0. The dashed line represents the vertical meridian (V1-V2 border). The opercular cortex (representing the central $8^{\circ}$ of

by generating an artificial mosaic of ocular dominance columns, similar in spacing, pattern, and scale to ocular dominance columns on the monkey operculum. In this artificial mosaic, the areas occupied by black and white columns were made precisely equal. The artificial mosaic then was traced by pen and ink onto an acetate sheet, scanned into the computer, and analyzed to calculate the median gray level. This median gray level then was used to set the threshold for determining black versus white in the quantitative analysis of the areas occupied by left eye and right eye columns in our drawings of the ocular dominance mosaics in the monkeys.

For comparison with the computer analysis, area measurements also were made manually by photocopying the drawings, cutting up the black and white columns, and weighing the paper. The weight of the black columns needed to be reduced by $11 \%$ to allow for the extra weight of the toner deposited on the paper.

\section{RESULTS}

Ocular dominance columns in newborn monkeys

Ocular dominance columns were clearly visible in striate cortex from each hemisphere in all four animals. Figure 1 shows a matching pair of autoradiographs from the left and right visual cortex of monkey 1, a dark-reared monkey delivered by Caesarean section at E157 and perfused at E165. More than half the surface area of each section was occupied by layer IVc, indicating that the 

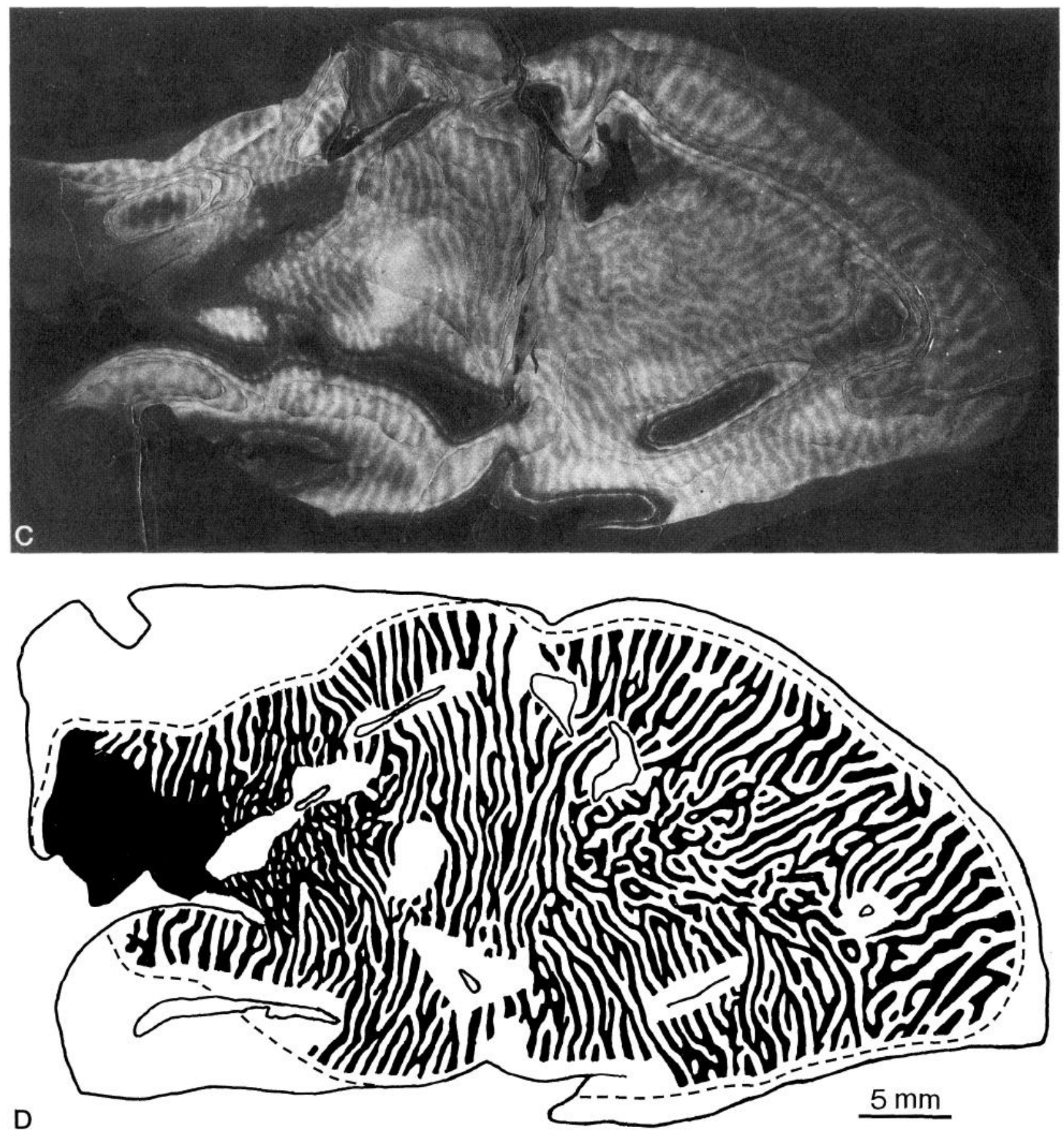

visual hemifield) is contained within the lateral half of each figure, whereas the cortex folded within the calcarine fissure (peripheral $8^{\circ}$ to $100^{\circ}$ ) occupies the medial half of each figure. Note that the columns in the cortex ipsilateral to the injected right eye $(C)$ are crisper than the columns in the contralateral cortex $(A)$, which is an effect observed in all monkeys.

cortex was flattened effectively by the unfolding procedure. The label was particularly robust in these newborn animals compared with the intensity of label typical in adult animals processed with similar methods. In every baby monkey, the intensity of the autoradiographic label varied systematically with eccentricity. The heaviest label was found in the peripheral field representation, whereas the foveal representation was labeled more faintly.

We prepared photomontages of the autoradiographs using serial alternate sections to reconstruct the pattern formed by the ocular dominance columns. Each photomontage incorporated data from 15-18 sections, although most of the column pattern was contained within six critical sections. Figure $2, A$ and $C$, shows photomontages of the columns in the left and right striate cortex of monkey 1, with matching pen-and-ink sketches (Fig. 2B,D). Approximately $90 \%$ of the column mosaic was reconstructed successfully in each hemisphere. Photomontages and sketches of the ocular dominance columns from monkey 2, another animal delivered by Caesarean section at E157, are shown in Figure 3. 

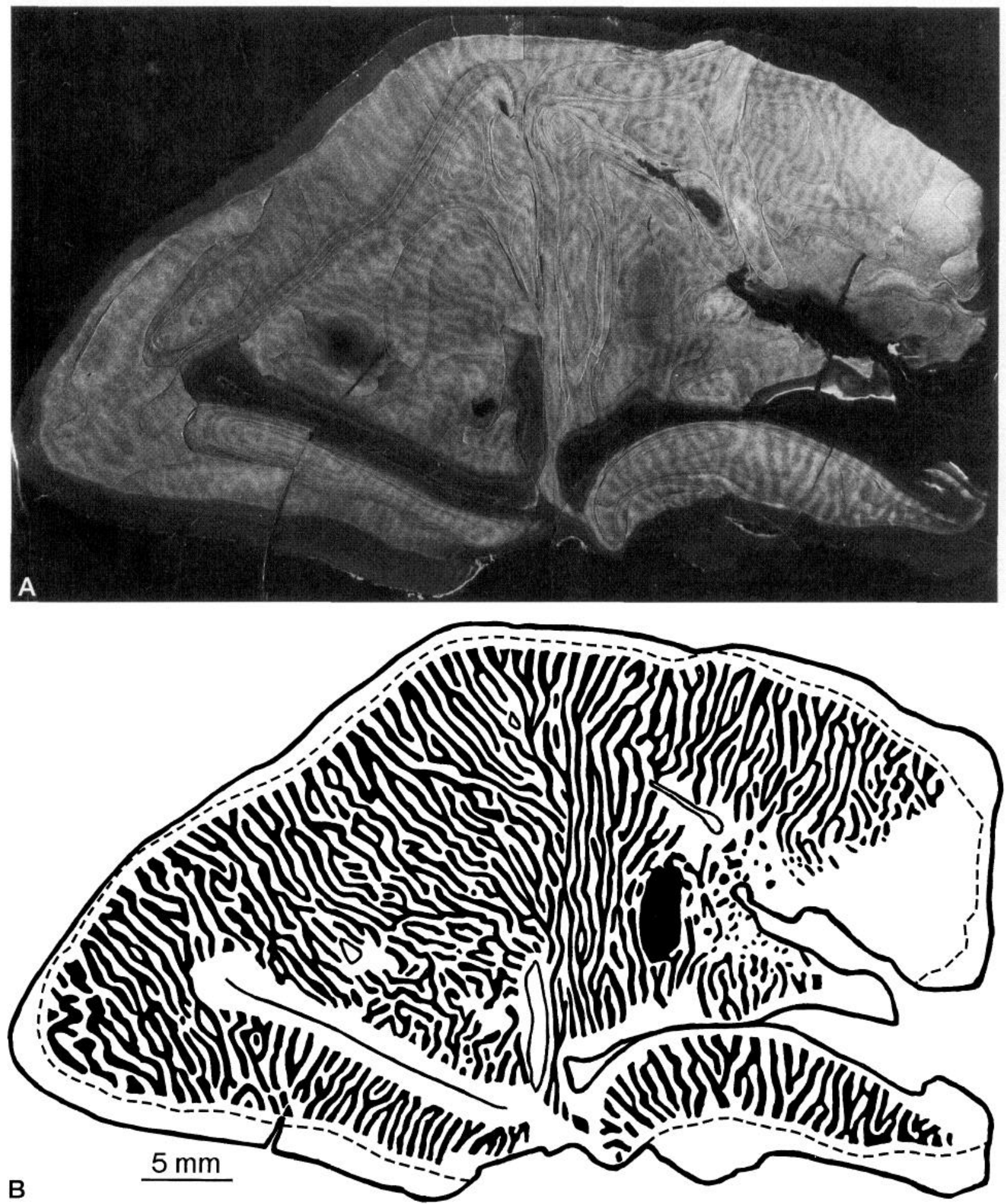

Figure 3. Left $(A, B)$ and right $(C, D)$ striate cortex from monkey 2, another E165/P0 animal studied before light exposure, showing well formed columns. The pattern of columns is finer than in monkey 1 , with thinner columns and more sets of columns. Such variability is common among normal animals.

Similar findings were observed in monkey 3 , the third dark-reared neonate, although photomontages and quantitative measurements were not made.

Looking at the column mosaics in Figures 2 and 3 , one is struck immediately by their similarity to the pattern of ocular dominance stripes reconstructed originally by LeVay et al. (1985) in the adult macaque monkey. As in the adult monkey, the columns appear as a system of parallel stripes, with frequent bifurcations, blind endings, and islands. They are oriented roughly perpendicular to the vertical meridian representation (V1-V2 border). In the flat region of cortex exposed over the lateral convexity of the occipital lobe (called the "operculum"), the columns form a raphe as they approach the horizontal meridian. By contrast, in striate cortex folded within the calcarine fissure, the columns run straight across 

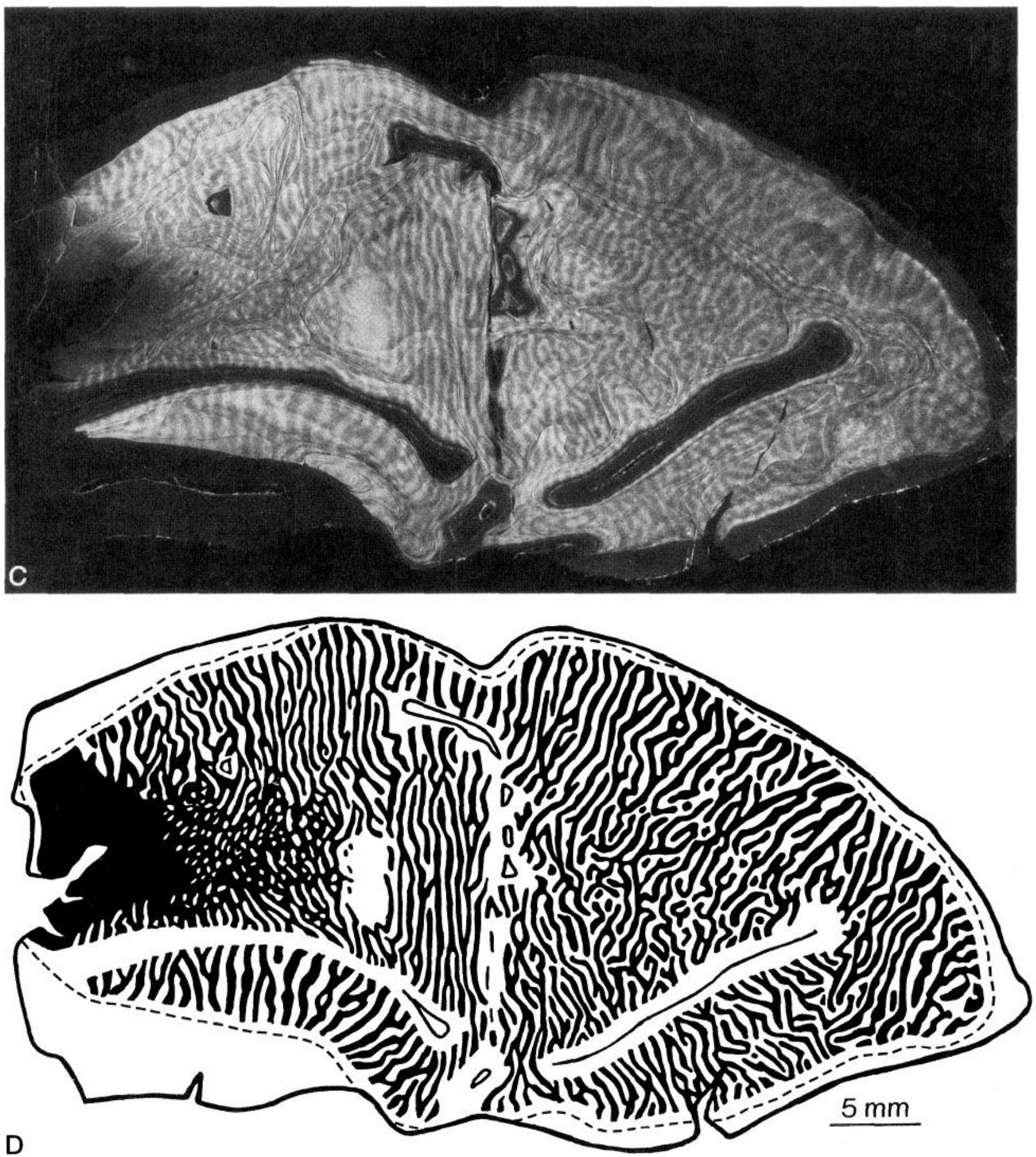

The intensity of autoradiographic label increases with eccentricity in the retinal map (label becomes more intense moving medially along each figure), which is a finding noted in all monkeys.

the short axis of V1. Within the operculum, representing the central $8^{\circ}$ of visual hemifield, the columns serving the ipsilateral and contralateral eyes occupy approximately equal areas (Table 1). Within the calcarine fissure, representing the peripheral visual field, the ocular dominance columns driven by the contralateral eye predominate. This imbalance occurs because in the periphery the columns serving the ipsilateral eye become thinner, especially near the horizontal meridian between the blind spot and the monocular crescent border, where they disintegrate into small islands. Columns were observed to be wider along the represen- tation of the vertical meridian than along the horizontal meridian, and wider within the representation of the central field than the periphery. Because of these two combined gradients, the foveal representation contained the fattest columns, and the peripheral field representation along the horizontal meridian contained the thinnest ipsilateral eye columns. Along the V1-V2 border (vertical meridian), there were 115-125 pairs of columns in each striate cortex, which agrees with the total of 113-118 pairs found by LeVay et al. (1985). Their average width along the V1-V2 border was $\sim 500 \mu \mathrm{m}$. In all hemispheres, the blind spot and monocular 

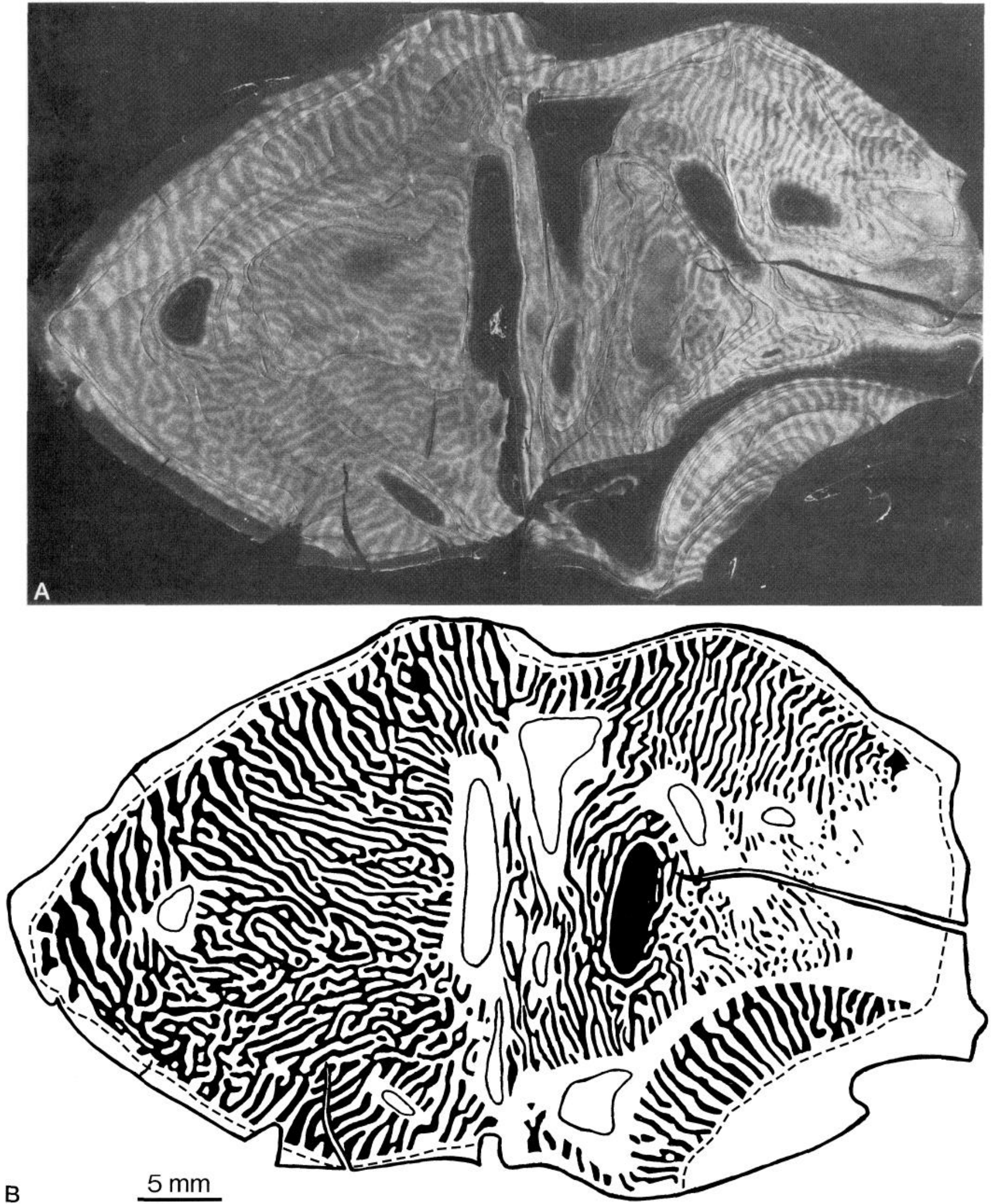

Figure 4. Left $(A, B)$ and right $(C, D)$ striate cortex from monkey 4 , raised in a normally lit nursery and perfused at P16. In the cortex ipsilateral to the 

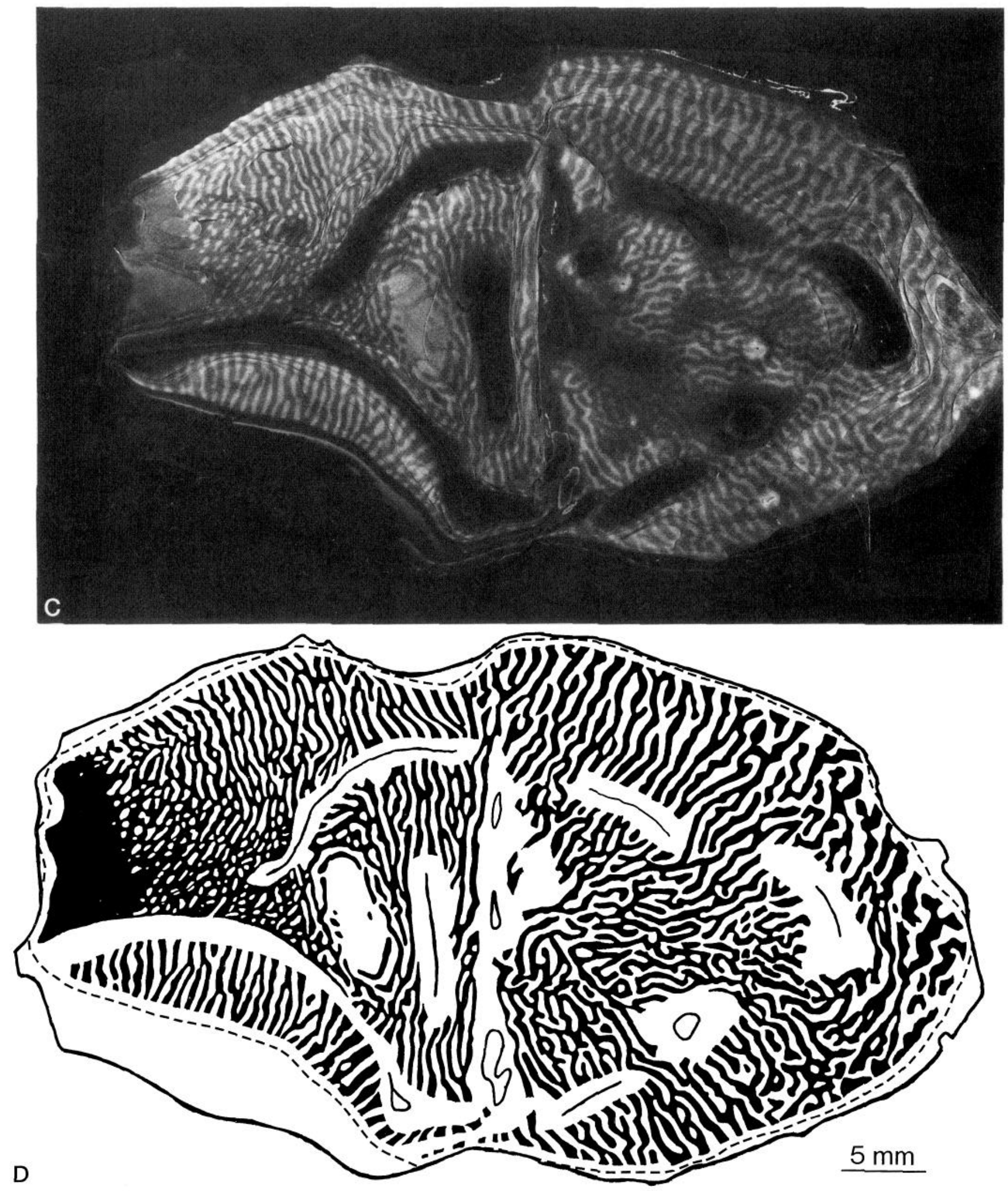

injected eye $(C)$, the columns appear to be as sharply segregated as in adult animals. As in all monkeys, the foveal representation contains the widest columns (see columns at the most lateral edges of the mosaics). 

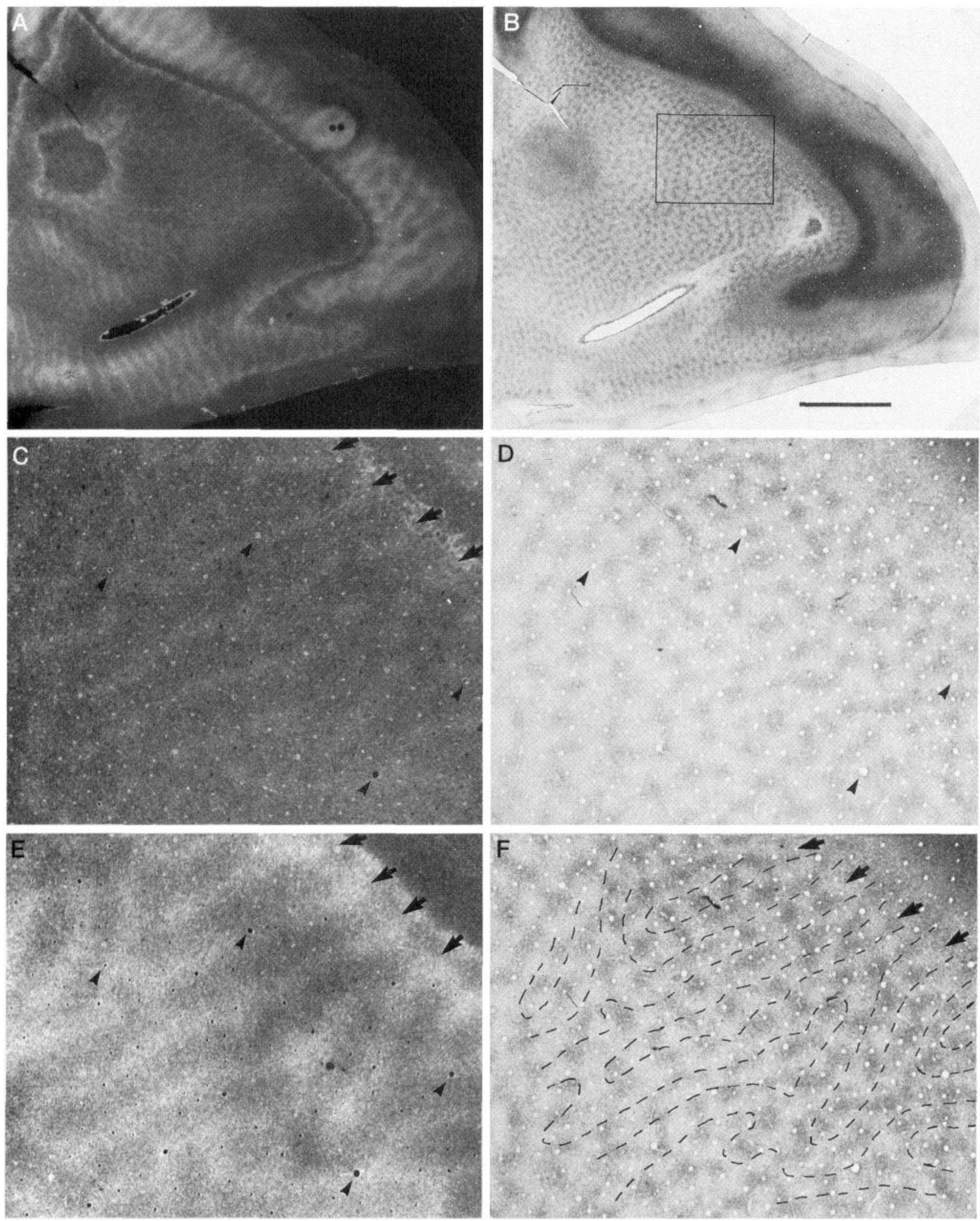
crescent representations were of the size and location expected within the overall column mosaic.

In these newborn monkeys, the pattern of ocular dominance columns was adult-like, but the borders of the columns were more blurred than in mature animals. To assess how rapidly the columns attain a degree of adult segregation, we examined a single monkey (monkey 4) born naturally at E165, raised under normal lighting conditions, and perfused at P16. The borders of the ocular dominance columns appeared much sharper than those in the newborn monkeys. In the left cortex (Fig. $4 A, B$ ), the columns still appeared slightly indistinct, but in the right cortex (Fig. $4 C, D$ ), ipsilateral to the eye injected with $\left[{ }^{3} \mathrm{H}\right]$ proline, the columns were as crisp as in adults. The total area of V1 was on average $26 \%$ greater than in the newborn monkeys, but the number of column pairs along the V1-V2 border was similar (Table 1). The representation of the blind spot was quite large and elongated. We have observed considerable variability in the appearance of the blind spot representation from animal to animal.

\section{Segregation of input to the CO patches}

$\mathrm{CO}$ patches are organized like pearls on a string, with each strand fitting in register with an ocular dominance column in layer IVc (Horton and Hubel, 1981; Horton, 1984). Patches receive direct input from the thalamus, which can be labeled directly by anterograde tracer injection into the lateral geniculate body, or transneuronally by tracer injection into the eye (Livingstone and Hubel, 1982; Fitzpatrick et al., 1983; Weber et al., 1983; Horton, 1984; Itaya et al., 1984). The source of the projection to the $\mathrm{CO}$ patches still is uncertain, but it may come from the small, intercalated cell layers of the lateral geniculate body. It also has remained unclear whether the projection to the patches is segregated by eye in normal monkeys.

In the newborn monkeys, strong autoradiographic label (Fig. $5 A$ ) was detected in layers II,III of striate cortex, where the CO patches were labeled best (Fig. $5 B$ ). In layer III, the proline label appeared organized into thin stripes (Fig. $5 C$ ), which ran down the center of each ocular dominance column labeled in layer IVc (Fig. $5 E$ ). The stripes of label in layer III were thinner than the ocular dominance columns in IVc (Fig. 5E) and were, in fact, the same width as the rows of $\mathrm{CO}$ patches (Fig. $5 D$ ). Comparison of autoradiographs and sections stained for $\mathrm{CO}$ showed an excellent match between the tritium label and the $\mathrm{CO}$ activity in every other row of patches (Fig. $5 C-F$ ). This finding indicates that input to the $\mathrm{CO}$ patches already is segregated by eye at birth.

The tritium label in layer III appeared organized into more continuous stripes compared with the more patchy distribution of $\mathrm{CO}$ activity. However, in layer II the autoradiographic label became more patchy, with a perfect match between each puff of tritium label and each labeled $\mathrm{CO}$ patch. Between each row of dense tritium label in layer III, one could detect faint puffs of autoradiographic label matching the $\mathrm{CO}$ patches of the uninjected left eye. This label represented either artifact from spillover of autoradiographic label or a weak input from the right eye to the patches of the left eye (see Discussion).

\section{Laminar arrangement of geniculocortical input in newborns}

The main focus of this paper is on the horizontal rearrangement of geniculocortical afferents into ocular dominance columns in newborns. However, it is worth reporting several features we observed of the vertical or laminar pattern of cortical organization in newborns, which differed strikingly from those observed in adults. Layer $\operatorname{IVc} \beta$ was subdivided by a label-sparse gap into a thin lower tier and a thick upper tier of geniculate input (Fig. 6A). This gap in layer IVc is not present in adult animals. The thick upper tier contained part of IVc $\beta$ and all of IVc $\alpha$. The density of $\mathrm{CO}$ mirrored exactly the distribution of geniculocortical terminals, with a band of pale staining dividing layer IVc $\beta$ into a thin, dark, lower sublayer and a thick, dark, upper sublayer that included IVc $\alpha$ (Fig. 6B). This dark, upper layer of $\mathrm{CO}$ activity, observed previously in E143 fetal monkeys (Horton, 1984) and in newborns (Kennedy et al., 1985), originally was thought to extend into layer IVb. With the geniculocortical projection now available in adjacent autoradiographs to define the upper extent of layer IVc, we realize that this layer of dark $\mathrm{CO}$ staining is located entirely within layer IVc, and does not intrude into layer IVb. In fetal and newborn monkeys, layer IVc is relatively thicker than in adults, whereas layer IVb is thinner and more poorly myelinated. In the P16 monkey, a more adult laminar pattern of geniculocortical projection and $\mathrm{CO}$ activity was present.

In newborn monkeys, the dark, thick layer of $\mathrm{CO}$ activity in the upper portion of layer IVc $\beta$ and layer IVc $\alpha$ contained a distinct pattern of patches (Fig. 7). By contrast, in normal adults, CO patches are not visible in layer IVc. The layer IVc patches in newborns were aligned with the patches in layers II,III and with the ocular dominance columns in layer IVc (Fig. 8). They appeared similar to the patches in the upper layers, but were fainter and more continuous. They were only faintly visible in the monkey at P16.

\section{Spillover of radioactivity in the lateral geniculate body}

In all four animals, the ocular dominance columns in the right visual cortex appeared better defined than the columns in the left visual cortex (Figs. 2-4). The sharper columns in the right cortex, ipsilateral to the injected eye, might represent a technical artifact caused by unequal spillover of label in the lateral geniculate body. For example, if more spillover of radioactivity occurred in the lateral geniculate body contralateral to the injected eye, the ocular dominance columns in the contralateral cortex would appear more blurred. We examined serial alternate autoradiographs of the left and right lateral geniculate body from each animal and found no evidence for such a pattern of asymmetric spillover. A representative matching pair of lateral geniculate bodies from

Figure 5. A, Right operculum from monkey 1 showing rows of tritiun label in layers II,III. The ocular clominance columns in layer IVc are visible around the top and right border of the section. $B$, An adjacent $\mathrm{CO}$ section at precisely the same magnification showing rows of patches in the upper layers. The area enclosed within the $b o x$ is illustrated in the next four panels $(C-F)$. Scale bar, $5 \mathrm{~mm}$. $C$, Higher-power view of $A$, showing thin rows of tritium label in layer III (arrows). Arrowheads mark four prominent blood vessels used for section alignment. $D$, Higher-power view of $B$, showing rows of CO patches. Notice that they appear more punctate than the rows of label in $C . E$, Ocular dominance columns in layer IVc from a deeper section. The thin rows of tritium label in $C$ run down the middle of each labeled ocular dominance column (arrows). $F$, Pattern of ocular dominance columns in $E$ has been traced onto section $D$, using matching radial blood vessels as fiduciary marks. The arrows match the arrows in $C$ and $E$ and show that only every other row of $\mathrm{CO}$ patches is labeled, indicating that input to the patches is segregated by eye at birth. 


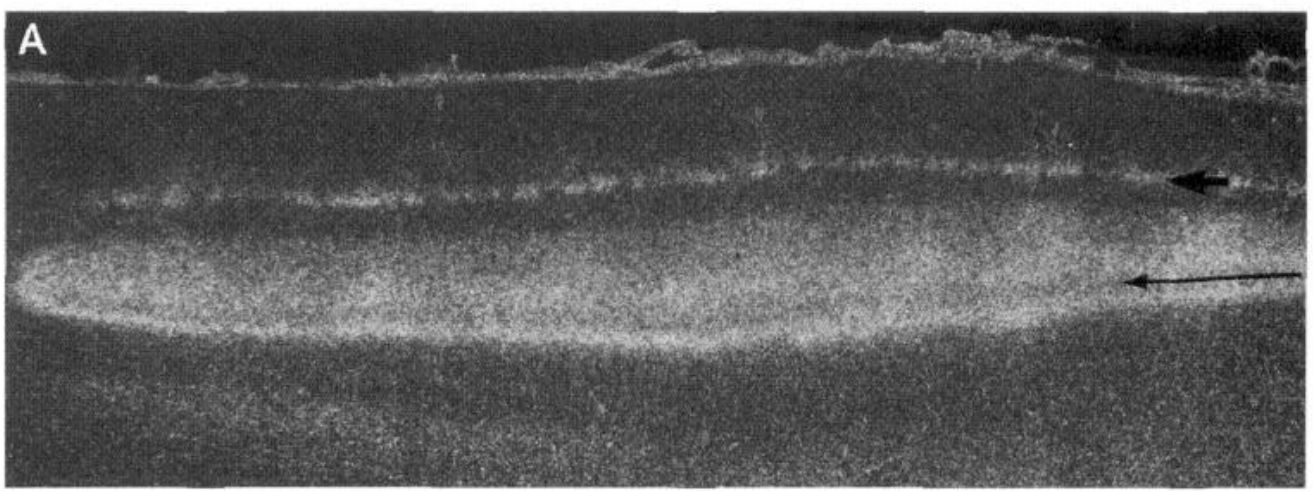

Figure 6. A, Autoradiograph of a crosssection of striate cortex from monkey 3 (E165/P0) showing laminar arrangement of geniculate input after injection of tritiated proline into the right eye. There is a gap in layer IVc $\beta$ (long arrow) that is not observed in adults. The upper tier of label (short arrow) corresponds to layer IVa (the "honeycomb"). V1-V2 border is at the far left. B, Adjacent section, showing matching $\mathrm{CO}$ staining. Layer IVc is split by a pale band (long arrow). By comparison with $A$, one can see that the dark $\mathrm{CO}$ activity corresponds perfectly to the distribution of silver grains in layer IVc representing geniculate input, with no extension of dark $\mathrm{CO}$ staining into IVb. Scale bar, $1 \mathrm{~mm}$.

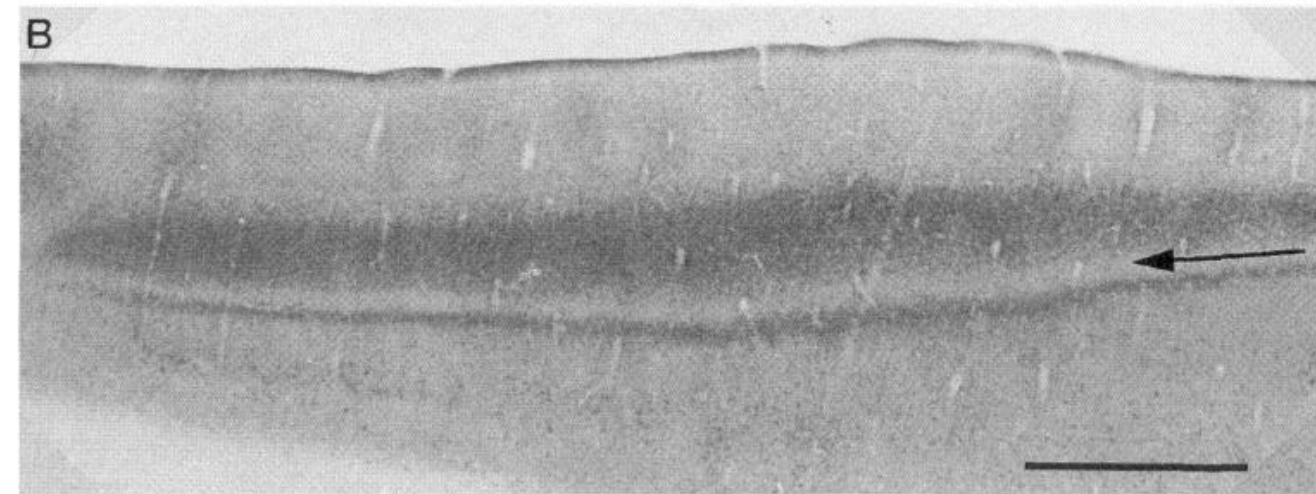

monkey 2 is shown in Figure 9. In this animal, the intensity and spillover of label appeared, if anything, slightly greater in the ipsilateral geniculate body.

\section{V2 stripes in newborns}

In adult monkeys, $\mathrm{V} 2$ contains a crude pattern of $\mathrm{CO}$ stripes oriented perpendicular to the V1-V2 border. Although the stripes are irregular and contain a complex internal pattern of fluctuating $\mathrm{CO}$ activity (Horton, 1984), their overall arrangement reflects a repeating cycle of thick-pale-thin-pale stripes (Tootell et al., 1983). In all three dark-reared newborn macaques, this organization of V2 stripes was obvious. The pattern of thick-pale-thin-pale V2 stripes surrounding the opercular portion of V1 in monkey 3 is shown in Figure 10. There were 15 stripe cycles along a distance of $53 \mathrm{~mm}$, for an average of 3.5 $\mathrm{mm} /$ cycle. Although fewer cycles of stripes were captured in single sections containing peripheral-field representation, because of technical factors related to our strategy for tissue flattening, we were able to count $\sim 26$ cycles of stripes in V2 from each specimen, or $\sim 13$ cycles for each half of $\mathrm{V} 2$.

\section{DISCUSSION}

\section{Ocular dominance columns in newborn monkeys}

All three newborn monkeys, studied at an age equivalent to $\mathrm{E} 165 / \mathrm{P} 0$, had well segregated ocular dominance columns in layers IVc $\beta$, IVc $\alpha$, and IVa in the absence of any light exposure. This result indicates that visual experience is not required for the formation of ocular dominance columns in striate cortex. Our findings confirm Rakic's observation $(1976,1977)$ that the process of segregation of geniculocortical afferents in monkeys begins during fetal life. It also is consistent with a deoxyglucose study by Des Rosiers et al. (1978) of a single light-exposed monkey showing clear ocular dominance columns after occluding one eye for 3 hr on the first day of life. Although deoxyglucose is a metabolic label, rather than a fiber-tracing method, this experiment pro- vided powerful evidence years ago that ocular dominance columns are formed before birth.

Controversy over the role of visual experience in the development of ocular dominance columns originally came from results obtained in experiments involving dark-reared animals. LeVay et al. (1980) found that ocular dominance columns were present in a monkey reared in complete darkness for 7 weeks. However, the animal was allowed normal vision for $3 \mathrm{~d}$ after birth, before initiation of darkrearing. This experiment, therefore, proved only that ocular dominance columns could withstand prolonged dark-rearing, but did not answer the question of whether visual experience is required for their initial formation. This issue first was raised directly by Swindale (1981), who reported that ocular dominance columns were absent in dark-reared cats. His results were questioned by Mower et al. (1985) and Stryker and Harris (1986), who found ocular dominance columns in dark-reared cats. Despite these contrary reports, in a subsequent study Swindale (1988) reaffirmed that dark-reared cats lack ocular dominance columns and concluded that "spontaneous activity present in the geniculocortical afferents of dark-reared and lidsutured cats is not adequate to drive normal periodic segregation in area 17."

All of the aforementioned studies are open to the criticism that a brief period of visual experience occurred either immediately after birth (before the babies were discovered and placed into the dark) or at the time of tracer injection into the eye. If a short pulse of light or visual experience were sufficient to activate the process of column segregation, even brief exposure in a young animal might be enough to invalidate a dark-rearing experiment. For this reason, we took special precautions to guard against inadvertent light exposure. After the second month of gestation, the pregnant mothers were housed in a dimly lit room to ensure that no significant amount of light could reach the developing fetus. For this to occur, light would have to penetrate through the mother's dark fur, skin, abdominal wall, omentum, uterus, and placenta to 

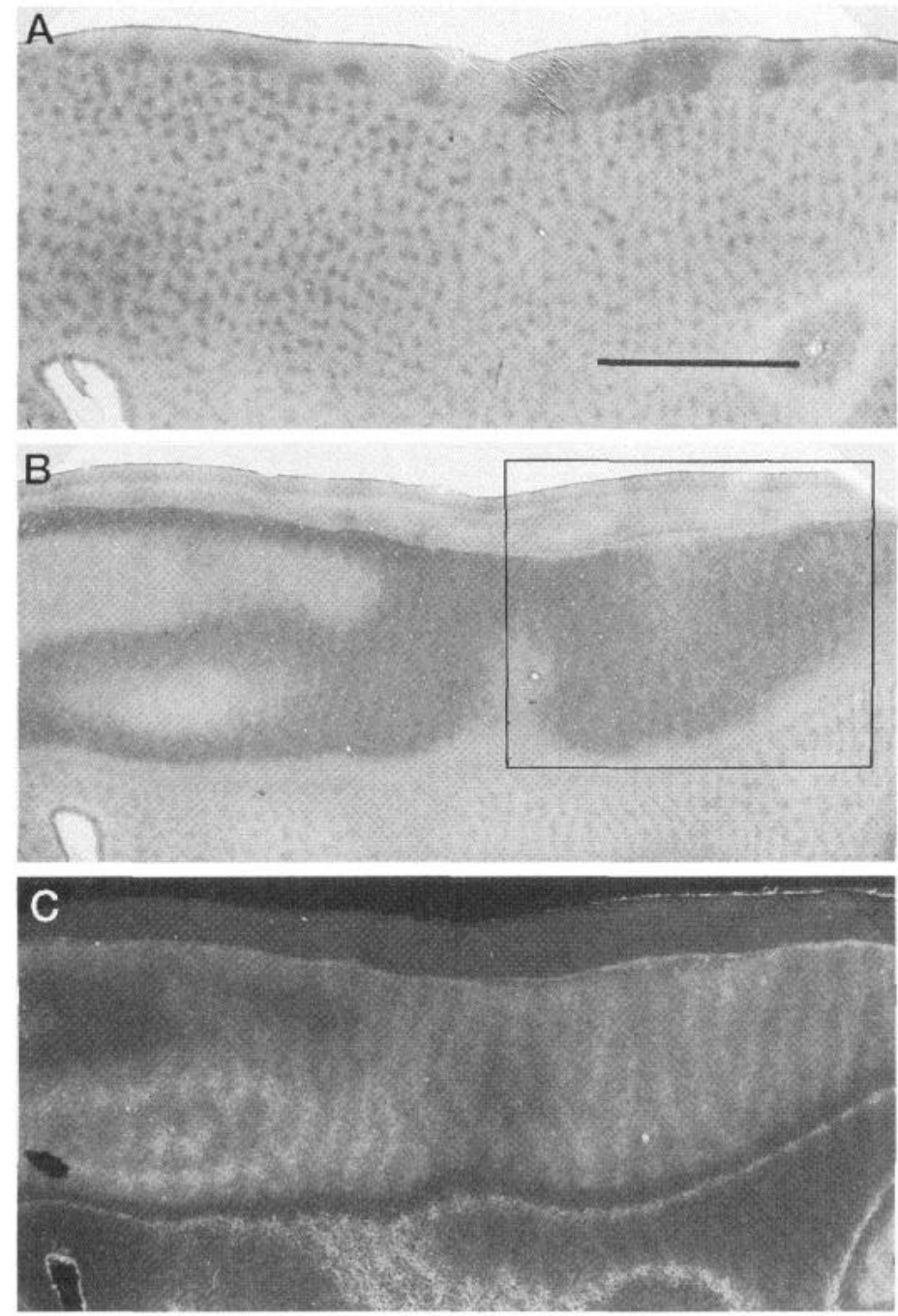

Figure 7. A, Layers II,III of left V1 from monkey 1 (E165/P0) showing rows of $\mathrm{CO}$ patches. $B$, Deeper section from the same block showing faint rows of patches in layer IVc. The area enclosed within the box is shown at higher magnification in Figure 8. C, Autoradiograph of an adjacent section showing the ocular dominance columns in IVc. Note that in layer IVa (honeycomb, bottom center), ocular dominance columns are also visible. Scale bar, $5 \mathrm{~mm}$; all panels are the same magnification.

reach the baby's eyes. During pregnancy, the myometrium thickens to $1 \mathrm{~cm}$, providing an extra barrier to light. Although we did not measure light levels inside the gravid uterus, the foregoing considerations make it doubtful that any significant antepartum light exposure occurred in our experiments. The Caesarean section, eye-injection, and animal care and feedings all were performed using infrared night-vision goggles to obviate the need for light during these procedures. Because of our strenuous efforts to eliminate light exposure, we feel secure in our conclusion that stimulation of the retina by light is not necessary for the development of ocular dominance columns in macaque visual cortex.

Although our results show that visually driven activity is not required for the development of ocular dominance columns, Stryker and Harris (1986) have found in cats that column formation can be blocked by repeated injection of tetrodotoxin into the eyes. Therefore, spontaneous activity in retinal ganglion cells is essential for the segregation of geniculocortical afferents into ocular dominance columns. Theorists have proposed that ocular dominance columns self-organize by the
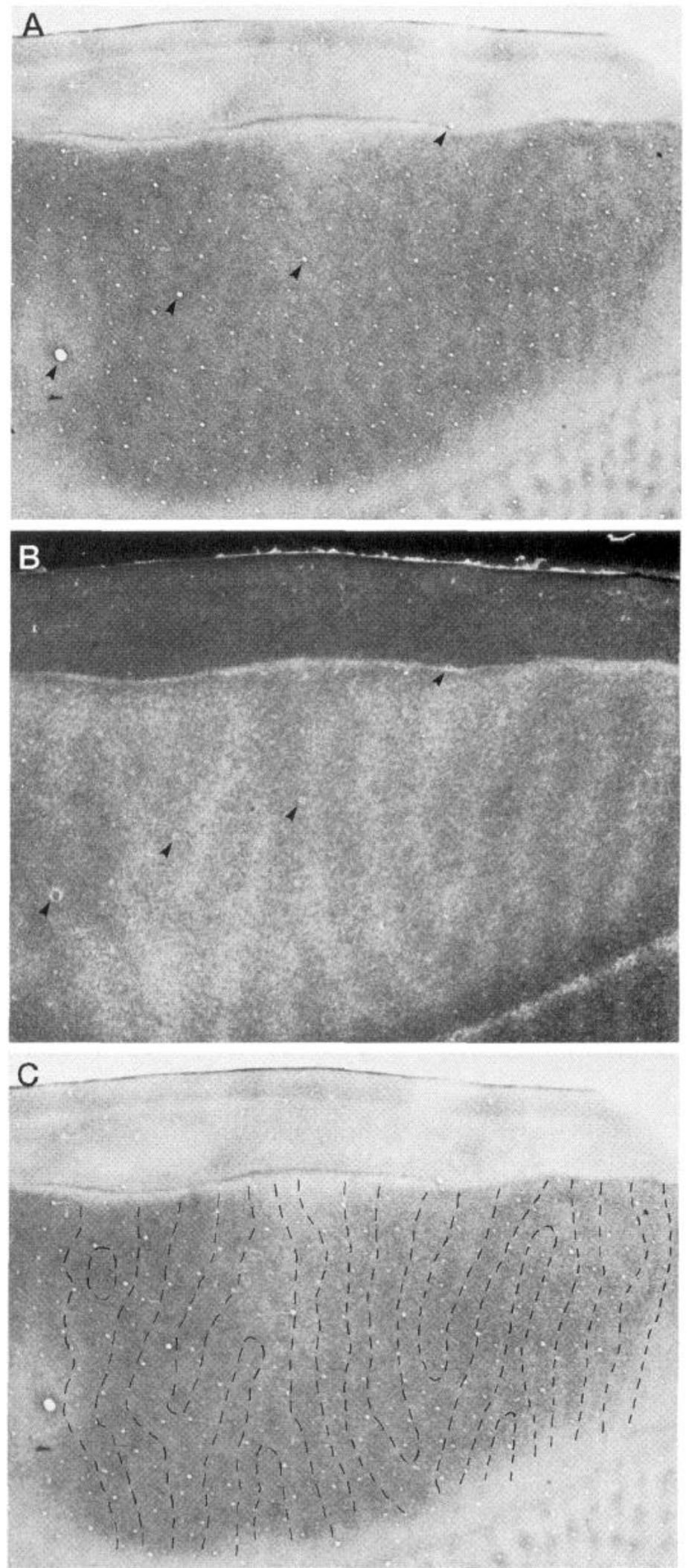

Figure 8. $A$, Higher-power view of the boxed area in Figure $7 B$. Note the patches in layer IVc, which are fainter and more continuous than those observed in layers II,III. Arrowheads show prominent blood vessels used for alignment of sections. $B$, Adjacent autoradiograph showing the ocular dominance columns in layer IVc. $C$, The borders of ocular dominance columns in $B$ have been traced onto $A$. The rows of $\mathrm{CO}$ patches run down the middle of the OD columns, but are thinner. The patches are evidence for a substructure within layer IVc in baby monkeys. 

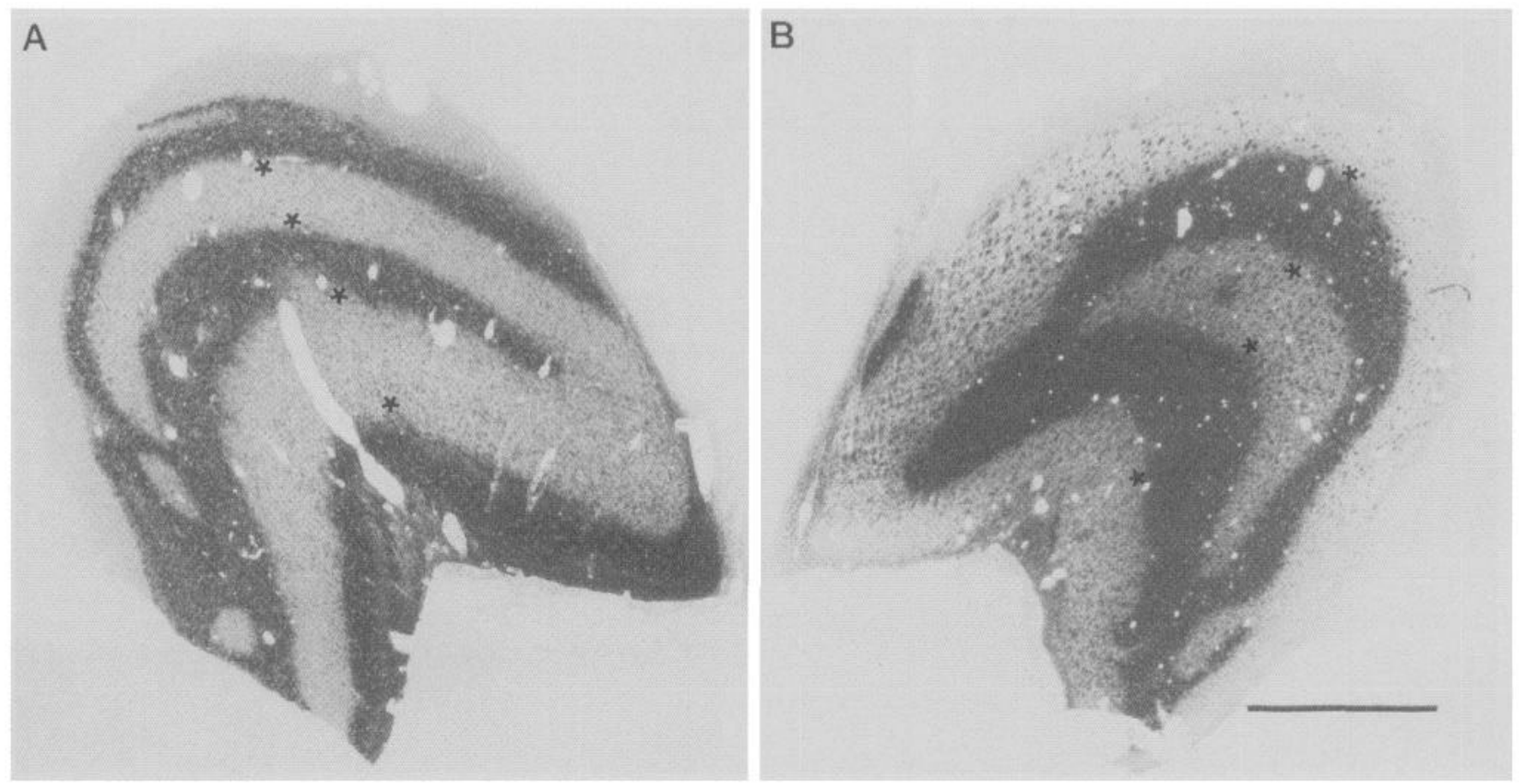

Figure 9. Bright-field autoradiographs of the left $(A)$ and right $(B)$ lateral geniculate bodies from monkey 2. There are four borders (asterisks) for potential spillover between labeled and unlabeled laminae on each side. The ipsilateral lateral geniculate body shows more spillover, but also more intense labeling. Scale bar, $1 \mathrm{~mm}$.

synchronous firing of cortical inputs driven by the same eye (von der Malsburg and Willshaw, 1976; Swindale, 1980; Miller et al., 1989; Jones et al., 1991). If so, this correlated firing must be spontaneous, because our present findings show that columns in monkeys develop before coordination of ocular inputs by visual stimulation could be a factor. A number of investigators have found evidence for such spontaneous firing patterns in the mammalian retina (Mastronarde, 1983; Maffei and GalliResta, 1990; Meister et al., 1991). More recently, a model has been proposed in which the width of ocular dominance columns is influenced by the degree of between-eye correlation in firing patterns (Goodhill, 1993). This model predicts wider columns in strabismic animals, because activity between the eyes is poorly correlated compared with normal animals. Evidence appearing to confirm this prediction has come from a study showing wider ocular dominance columns in cats rendered strabismic by cutting the medial rectus muscle at age 2-3 weeks (Löwel and Singer, 1993; Löwel, 1994). However, we doubt that this result would pertain to the monkey, given that its columns are well formed at birth, before visual experience could affect their width or periodicity. For such an effect to occur, the columns would have to disintegrate, regroup at a new periodicity, and shift the location of $\mathrm{CO}$ patches with them. Models for the development of ocular dominance columns that incorporate factors related to visual experience are unlikely to be relevant in monkeys, and we predict that no postnatal visual stimulus will be found that is capable of perturbing the pattern and periodicity of ocular dominance columns in macaque striate cortex, although, of course, columns can be shrunken or even obliterated by lesions or visual deprivation.

In the single animal studied 2 weeks after birth, the ocular dominance columns were better segregated than in the newborn monkeys, confirming that development of ocular dominance columns continues after birth. In the 2-week-old monkey, the columns appeared almost as well formed as those in adult monkeys, indicating that the process of column segregation is nearly over just a few weeks after birth. It would be interesting to dark-rear monkeys after birth to see whether deprivation can retard or reduce the final stages of column segregation, as has been claimed in the cat. However, the sharpness of autoradiographic labeling can vary from animal to animal for technical reasons, and given how clear the columns already look in newborns, it might be difficult to discern any consistent effects from binocular visual deprivation after birth unless large numbers of animals were studied.

\section{An adult-like pattern of ocular dominance columns in newborn monkeys}

By preparing complete, flat-mounted sections of V1 in each monkey, we could determine that ocular dominance columns are not only well segregated in newborns but also are organized into the characteristic pattern found in adult animals. This finding indicates that the intricate and stereotypic layout of the columns in V1 is ordained by intrinsic or innate factors and is not influenced by visual experience or eye alignment. Two familiar landmarks, the blind spot (12-18 eccentricity) and the monocular crescent bor$\operatorname{der}\left(55^{\circ}\right.$ eccentricity), were found exactly where they are located in adult animals, suggesting that no major shifts occur in the retinotopic map in V1 as the cortex grows after birth. In our newborn monkeys, the average area of $\mathrm{V} 1$ was $986 \mathrm{~mm}^{2}$, compared with an average of $1251 \mathrm{~mm}^{2}$ in the 2 -week-old animal. This represents a $26 \%$ postnatal increase, in fair agreement with estimates of $20 \%$ by Hubel et al. (1977) and $16 \%$ by Purves and LaMantia (1993). The total area of V1 varies considerably among rhesus monkeys and, therefore, the average growth of $16 \%$ calculated from 21 monkeys by Purves and LaMantia (1993) should be taken as the most reliable figure.

In baby human V1, it was noted previously that striate cortex is 


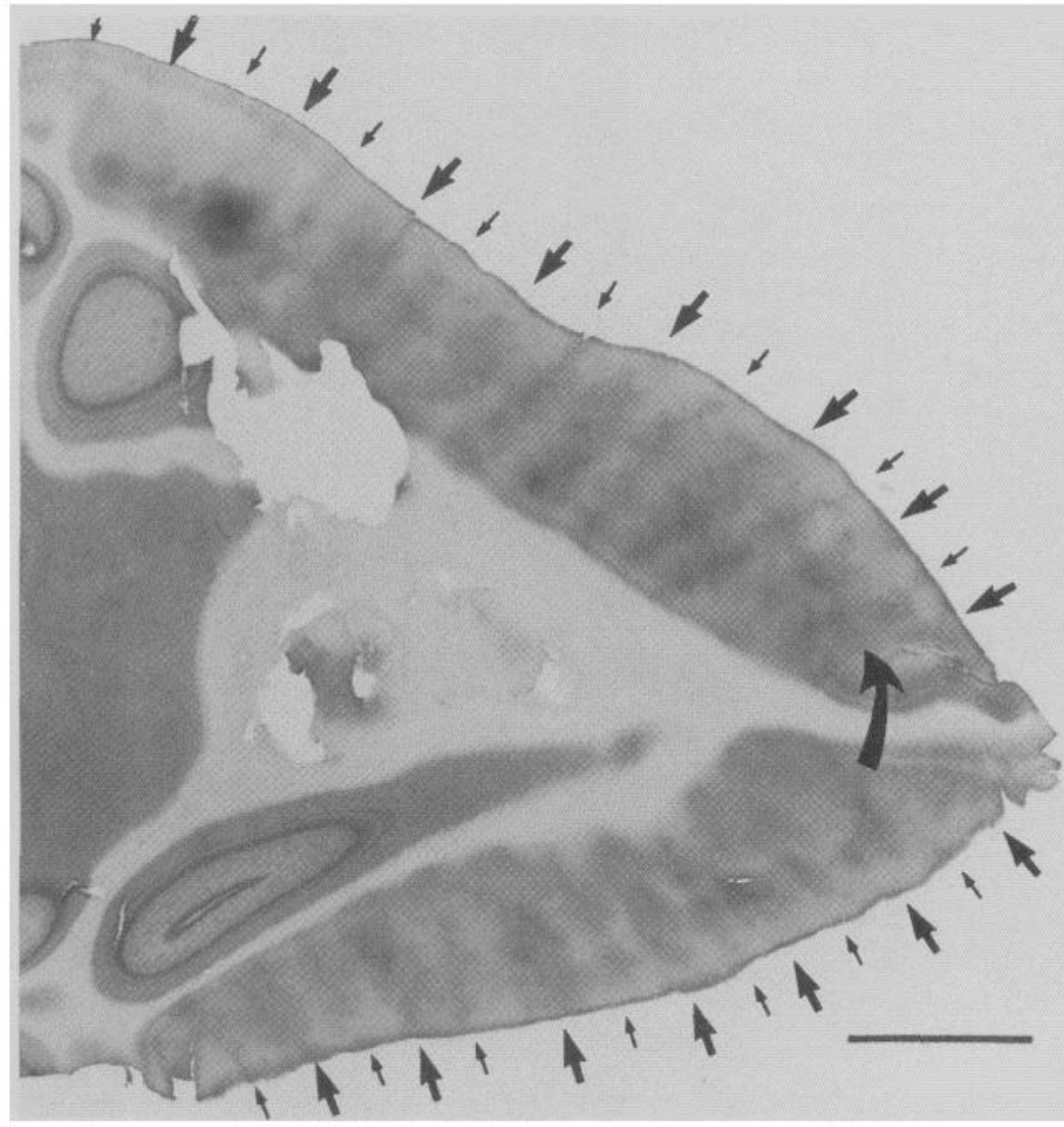

Figure 10. Single section showing 15 cycles of thick-palethin-pale CO stripes in V2 surrounding right opercular V1 from dark-reared monkey 3 (E165/P0). Note complex fluctuations in $\mathrm{CO}$ activity within each thick (large arrows), thin (small arrows), and pale stripe, as well as the overall repeating cycle pattern. In some areas, the hot spots of $\mathrm{CO}$ activity appear aligned into an orthogonal set of rows that bridge the stripes (curved arrow). Scale bar, $5 \mathrm{~mm}$. smaller than in adults and that the CO patches are smaller and more closely spaced (Horton and Hedley-Whyte, 1984). We suggested that as the cortex expands, the patches increase proportionately in size and become more widely separated. Evidence for this process has been adduced by Purves and LaMantia (1993), who reported that as the cortex grows, the total number of patches remains constant but their density falls by $18 \%$. In the present study, we have found a similar effect for the ocular dominance columns. The number of pairs of ocular dominance columns along the V1-V2 border remained about the same from birth to age 2 weeks, at least within the bounds of inter-animal variability, but the average column width increased as the V1 perimeter expanded (Table 1). In V2, the number of stripe cycles in newborns also matched the number reported in adult animals (Van Essen et al., 1990; Roe and Ts'o, 1995).

\section{Thalamic input to the patches already is segregated by eye at birth}

Because $\mathrm{CO}$ patches are centered in the middle of ocular dominance columns and contain cells with a strong eye preference, one might expect their thalamic input to be segregated by eye. Itaya et al. (1984) reported an "approximate one to one ratio" between labeled patches and ocular dominance columns after eye injection of wheat germ agglutin-horseradish peroxidase in a monocularly blind monkey.

Our results after proline eye injection confirm that the transsynaptic input to the patches in layers II,III is organized by eye and show that segregation of input already is well established at birth. However, the pattern of the proline label did not match exactly the pattern of $\mathrm{CO}$ activity. The proline label was more continuous, tending to fill in the space between patches along each row (Fig. 5). It would be interesting to examine older monkeys to determine whether the thalamic projection becomes more sharply confined to the patches as the cortex matures. It also would be interesting to study fetal monkeys to learn whether the projection to the $\mathrm{CO}$ patches comes from a diffuse projection of intermingled thalamic afferents in layers II,III that later retracts and segregates to the $\mathrm{CO}$ patches, or whether it is localized to the rows of patches and segregated by eye from the beginning. If the latter situation applies, it would indicate that a pattern of columnar projection can become segregated by eye without the intermediate stage of binocular overlap and competitive sorting that some investigators believe is essential for column formation in layer IVc. These alternative models for the development of complex iterative circuits have been reviewed by Purves (1994).

\section{A different laminar arrangement of geniculate input and $\mathrm{CO}$ activity in neonatal cortex}

Although we have emphasized in this report how mature the ocular dominance columns appear at birth, the geniculocortical projection differs in newborns versus adults. Not only are the columns less completely segregated, but the laminar pattern of cortical innervation is distinct. In newborns, layer IVc $\beta$ contains a terminal sparse tier, giving it a railroad-track appearance, and layer IVc is comparatively thicker than in adults (Fig. 6). Therefore, refinement of the geniculate input to the growing cortex involves a relative reduction in the vertical extent of layer IVc, loss of the label-free gap in layer IVc $\beta$, and completion of column segregation. Presumably, development of the stria of Gennari (layer IVb), which appears more poorly myelinated in newborns, contributes to the relative reduction of layer IVc as the cortex 
grows and thickens. There also may be a slight decrease in the absolute thickness of layer IVc.

Layer $I V c \beta$ in newborn monkeys contains a tier of weak $\mathrm{CO}$ staining, giving it a bilaminate appearance, perfectly matching the pattern of geniculocortical innervation (Fig. 6). The dark band of staining in layer IVc contains rows of $\mathrm{CO}$ patches. These patches are in register with the patches in other layers, but appear fainter and less punctate. They form thin rows that run down the middle of the ocular dominance columns in layer IVc, subdividing them into cytochrome-rich "core zones" and cytochrome-poor "border strips." This subdivision of the ocular dominance columns in layer IVc suggests that cells along the borders of columns may differ in their physiological properties from those located within the cores of columns. Although the patches in layer IVc disappear as monkeys grow, our previous experiments with visual deprivation in adult animals provide some evidence that this subdivision of layer IVc persists. We found in adult monkeys subjected to unilateral eyelid suture a curious pattern of fat, pale $\mathrm{CO}$ bands alternating with thin, dark $\mathrm{CO}$ bands in layer IVc (Horton, 1984). This puzzling finding was explained by invoking a subdivision of layer IVc into core zones and border strips, which is reminiscent of the pattern of $\mathrm{CO}$ staining observed in layer IVc of young monkeys.

\section{Do columns serving the ipsilateral eye segregate faster or more completely?}

By reconstructing the entire pattern of ocular dominance columns in newborn monkeys, we hoped to determine whether the columns display a gradient in their rate of maturation. For example, the columns in the foveal representation might develop faster than those in the periphery. Examining the autoradiographic photomontages, we could find no reliable evidence for such a gradient; the columns appeared about equally well developed throughout the binocular cortex. In the periphery, the columns were labeled more robustly, but this was attributable to more intense accumulation of label in that region. The tendency for columns to label more intensely in the periphery has been noted before (LeVay et al., 1978). It may be an artifact caused by more efficient uptake of label by ganglion cells in the peripheral retina, where they are larger and more thinly packed than in the central retina.

We also examined our autoradiographs to determine whether inputs driven by the two eyes segregate at different rates. In all animals, the labeled columns appeared more distinct in cortex ipsilateral to the injected eye. This effect has been reported previously in the cat (Shatz et al., 1977), and it was discounted as artifact from greater spillover of label in the lateral geniculate body contralateral to the injected eye (LeVay et al., 1978). The increased spillover was attributed to two factors. First, in the contralateral lateral geniculate body, lamina A1 (unlabeled) is sandwiched between laminae A and $C$ (labeled), causing contamination from both sides. In contrast, on the ipsilateral side, the spillover into lamina A (unlabeled) occurs only along the ventral border with lamina A1 (labeled). Second, in the lateral geniculate body contralateral to the injected eye, fibers of passage spill label into Al (unlabeled) on their way to lamina A (labeled), whereas in the ipsilateral lateral geniculate body, fibers projecting to lamina A1 (labeled) do not pass through lamina A (unlabeled). Although these arguments are persuasive in the cat, neither applies in the monkey. First, in the macaque, the number of interfaces for potential spillover between labeled and unlabeled laminae is the same in each lateral geniculate body. Second, although fibers of passage potentially may cause more spillover in the parvo layers of the contralateral lateral geniculate body, in the ipsilateral lateral geniculate body they create more opportunity for spillover in the magno layers. If spillover from fibers of passage were a major factor, one would expect fuzzier columns in cortical layer IVc $\beta$ (parvo-receiving layer) contralateral to the injected eye and fuzzier columns in layer IVc $\alpha$ (magno-receiving layer) ipsilaterally. In fact, we observed fuzzier columns in both layers IVc $\beta$ and IVc $\alpha$ in the contralateral cortex, making it difficult to explain the sharper ipsi columns by invoking unequal spillover from fibers of passage. We conclude that in the macaque the laminar architecture of the lateral geniculate body does not offer more opportunities for spillover of label on one side or the other. The sharper columns observed in ipsilateral cortex may indicate that the geniculocortical afferents serving the ipsilateral eye retract to their column boundaries slightly earlier or more completely than those serving the contralateral eye, although it is impossible to be sure because of the spillover issue. The best way to study this issue would be to fill the terminal arbors of individual geniculocortical afferents serving each eye to compare their relative degree of segregation in layer $I V c \beta$.

\section{CONCLUSIONS}

The catch phrase "nature versus nurture" encapsulates a debate central to developmental biology: how does the interplay between genetic instructions and environmental factors result in a normal, mature organism? This study adds to previous work showing that topographic organization, receptive-field properties, and orientation columns all develop in the mammalian visual cortex without any contribution from visual stimuli (Hubel and Wiesel, 1963; Wiescl and Hubel, 1974; Blakemore and Van Sluyters, 1975). We report that in macaques, an adult-like pattern of ocular dominance columns in V1 and CO stripes in V2 is present at birth. The CO patches in V1, which form in utero (Horton, 1984) without cues from photoreceptors (Kuljis and Rakic, 1990), receive an input segregated by eye at birth. Evidently, the functional architecture of the macaque visual cortex develops according to an innate program, independent of light or visual stimulation, although it can be disrupted profoundly by abnormal visual experience after birth (Wiesel, 1982).

\section{REFERENCES}

Blakemore C, Van Sluyters RC (1975) Innate and environmental factors in the development of the kitten's visual cortex. J Physiol (Lond) 248:663-716.

Des Rosiers MH, Sakurada O, Jehle J, Shinohara M, Kennedy C, Sokoloff L (1978) Functional plasticity in the immature striate cortex of the monkey shown by the $\left[{ }^{14} \mathrm{C}\right]$ de oxyglucose method. Science $200: 447-449$.

Fitzpatrick D, Itoh K, Diamond IT (1983) The laminar organization of the lateral geniculate body and the striate cortex in the squirrel monkey (Saimiri sciureus). J Neurosci 3:673-702.

Goodhill GJ (1993) Topography and ocular dominance: a model exploring positive correlations. Biol Cybern 69:109-118.

Horton JC (1984) Cytochrome oxidase patches: a new cytoarchitectonic feature of monkey visual cortex. Philos Trans R Soc Lond [Biol] 304:199-253.

Horton JC, Hedley-Whyte ET (1984) Mapping of cytochrome oxidase patches and ocular dominance columns in human visual cortex. Philos Trans R Soc Lond [Biol] 304:255-272.

Horton JC, Hubel DH (1981) Regular patchy distribution of cytochrome oxidase staining in primary visual cortex of macaque monkey. Nature 292:762-764.

Hubel DH, Wiesel TN (1963) Receptive fields of cells in striate cortex of very young, visually inexperienced kittens. J Neurophysiol 26:994 1002.

Hubel DH, Wiesel TN, LeVay S (1977) Plasticity of ocular dominance columns in monkey striate cortex: Philos Trans R Soc Lond [Biol] 278:377-409.

Itaya SK, Itaya PW, Van Hoesen GW (1984) Intracortical termination of the retino-geniculo-striate pathway studied with transsynaptic tracer (wheat germ agglutinin-horseradish peroxidase) and cytochrome oxidase staining in the macaque monkey. Brain Res 304:303-310. 
Jones DG, Van Sluyters RC, Murphy KM (1991) A computational model for the overall pattern of ocular dominance. J Neurosci 11:3794-3808.

Kennedy H, Bullier J, Dehay C (1985) Cytochrome oxidase activity in the striate cortex and lateral geniculate nucleus of the newborn and adult Inacaque monkey. Exp Brain Res 61:204-209.

Kuljis RO, Rakic P (1990) Hypercolumns in primate visual cortex can develop in the absence of cues from photoreceptors. Proc Natl Acad Sci USA 87:5303-5306.

LeVay S, Stryker MP (1979) The development of ocular dominance columns in the cat. In: Society for Neuroscience symposium: aspects of the developmental neurobiology (Ferrendelli JA, ed), pp 83-98. Bethesda: Society for Neuroscience.

I.eVay S, Connolly M, Houde J, Van Essen DC (1985) The complete pattern of ocular dominance stripes in the striate cortex and visual field of the macaque monkey. J Neurosci 5:486-501.

LeVay S, Stryker MP, Shatz CJ (1978) Ocular dominance columns and their development in layer IV of the cat's visual cortex: a quantitative study. J Comp Neurol 179:223-244.

LeVay S, Wiesel TN, Hubel DH (1980) The development of ocular dominance columns in normal and visually deprived monkeys. J Comp Neurol 191:1-51.

Livingstone MS, Hubel DH (1982) Thalamic inputs to cytochrome oxidase-rich regions in monkey visual cortex. Proc Natl Acad Sci USA 79:6098-6101.

Löwel S (1994) Ocular dominance column development: strabismus changes the spacing of adjacent columns in cat visual cortex. J Neurosci $14: 7451-7468$.

Löwel S, Singer W (1993) Strabismus changes the spacing of ocular dominance columns in the visual cortex of cats. Soc Neurosci Abstr 19:359.

Maffei L, Galli-Resta L (1990) Correlation in the discharges of neigh boring rat retinal ganglion cells during prenatal life. Proc Natl Acad Sci USA 87:2861-2864.

Mastronarde DN (1983) Correlated firing of cat retinal ganglion cells. II. Responses of $\mathrm{X}$ - and $\mathrm{Y}$-cells to single quantal events. J Neurophysiol 49:325-349.

Meister M, Wong ROL, Baylor DA, Shatz CJ (1991) Synchronous bursts of action potentials in ganglion cells of the developing mammalian retina. Science 252:939-943.

Miller KD, Keller JB, Stryker MP (1989) Ocular dominance column development: analysis and simulation. Science 245:605-615.

Mower GD, Caplan CI, Christen WG, Duffy FH (1985) Dark rearing prolongs physiological but not anatomical plasticity of the cat visual cortex. J Comp Neurol 235:448-466.

Mower GD, Christen WG, Caplan CJ (1983) Very brief visual experience eliminates plasticity in the cat visual cortex. Science 221:178-180.

Purves D (1994) Neural activity and the growth of the brain. Cambridge: Cambridge UP.
Purves D, LaMantia A (1993) Development of blobs in the visual cortex of macaques. J Comp Neurol 334:169-175.

Rakic P (1976) Prenatal genesis of connections subserving ocular dominance in the rhesus monkey. Nature 261:467-471.

Rakic P (1977) Prenatal development of the visual system in rhesus monkey. Philos Trans R Soc Lond [Biol] 278:245-260.

Roe AW, Ts'o DY (1995) Visual topography in primate V2: multiple representation across functional stripes. J Neurosci 15:3689-3715.

Rosen KM, McCormack MA, Villa-Komaroff L, Mower GD (1992) Brief visual experience induces immediate early gene expression in the cat visual cortex. Proc Natl Acad Sci USA 89:5437-5441.

Shatz CJ, Lindström S, Wiesel TN (1977) The distribution of afferents representing the right and left eyes in the cat's visual cortex. Brain Res 131:103-116.

Stryker MP, Harris WA (1986) Binocular impulse blockade prevents the formation of ocular dominance columns in cat visual cortex. J Neurosci 6:2117-2133.

Swindale NV (1980) A model for the formation of ocular dominance stripes. Proc R Soc Lond [Biol] 208:243-264.

Swindale NV (1981) Absence of ocular dominance patches in darkreared cats. Nature 290:332-333.

Swindale NV (1988) Role of visual experience in promoting segregation of eye dominance patches in the visual cortex of the cat. J Comp Neurol 267:472-488.

Tootell RBH, Silverman MS, De Valois RL, Jacobs GH (1983) Functional organization of the second cortical visual area in primates. Science 220:737-739.

Van Essen DC, Felleman DJ, DeYoe EA, Olavarria J, Knierim J (1990) Modular and hierarchical organization of extrastriate visual cortex in the macaque monkey. Cold Spring Harb Symp Quant Biol 55:679-696.

von der Malsburg C, Willshaw DJ (1976) A mechanism for producing continuous neural mappings: ocularity dominance stripes and ordered retino-tectal projections. Exp Brain Res [Suppl] 1:463-469.

Weber JT, Huerta MF, Kaas JH, Harting JK (1983) The projections of the lateral geniculate nucleus of the squirrel monkey: studies of the interlaminar zones and the S layers. J Comp Neurol 213:135-145.

Wiesel TN (1982) Postnatal development of the visual cortex and the influence of environment. Nature 299:583-591.

Wiesel TN, Hubel DH (1974) Ordered arrangement of orientation columns in monkeys lacking visual experience. J Comp Neurol 158:307-318.

Wong-Riley M (1979) Changes in the visual system of monocularly sutured or enucleated kittens demonstrable with cytochrome oxidase histochemistry. Brain Res 171:11-28. 